\title{
Imaginação, po- der e ciência: considerações acerca do filme Contato Extraterrestre
}

Carlos Roberto Winckler Doutorando em Sociologia/UFRGS Professor da FAMECOS/PUCRS
Contato ExtraterRestre é um bom exemplo de que é possível vida inteligente no planeta Hollywood.

Teria tudo para ser apenas mais um filme-espetáculo tão ao gosto, nesta década, das platéias contemporâneas mobilizadas pela ação e pirotecnia tecnológica e que supõem ser a humanidade um mero compósito de sensações nervosas.

No entanto, o bom roteiro, baseado em obra homônima de Carl Sagan, ${ }^{1}$ permite uma leitura complexa e matizada de diferentes respostas - não necessariamente excludentes - dadas às formas de conhecimento possíveis da realidade, examina as relações tensas entre compromissos político-institucionais e a busca da verdade e, principalmente, restitui à ciência uma dimensão poética esquecida nestes tempos de legitimação pela eficácia.

O filme, em síntese, trata dos esforços da brilhante rádio-astrônoma Ellie Arroway para manter sua base de escuta de sinais que, eventualmente, provariam a possibilidade de vida extraterrestre. Tal linha de pesquisa encontra forte oposição de David Drumlin da Fundação Nacional de Ciências dos EUA, dada a sua falta de perspectivas práticas. O projeto acaba por ser cancelado. Não obstante, encontra apoio e financiamento do excêntrico megaempresário S. R. Hadden.

As tentativas de Ellie Arroway acabam não sendo em vão. Sinais em código, vindos da estrela Vega, distante apenas a vinte e cinco anos-luz da Terra, abrem a perspectiva de contatos extraterrestres. O projeto, em que pese ser civil e privado, retorna ao 
controle do Conselho de Segurança Nacional. Entrementes, os sinais decodificados e traduzidos em imagens, revelam os planos de construção de uma máquina que, após intensos debates, imagina-se ser uma espécie de transporte à estrela Vega.

Em meio à forte comoção da opinião pública, despertada no que há de pior e melhor, organiza-se em um pool internacional de diferentes países e empresas que financia a construção de custosa máquina e, através de um comitê, decide-se quem irá à Vega. A primeira tentativa falha devido ao atentado de um fundamentalista cristão que destrói a máquina; a segunda tentativa com Ellie Arroway aparentemente também fracassa. A cápsula é projetada no mar. Todavia, a experiência vivida por Ellie Arroway passase em outro plano temporal e dimensional. Seu relato é desacreditado em depoimento público realizado no Congresso Nacional.

Não há imagens gravadas, não há provas de sua experiência, mas há algo que permanece oculto da opinião pública - o tempo de gravação de estática teria durado dezoito horas. Resta a memória da experiência vivida e a vivacidade de seu relato, que somente a poesia, poder da imaginação como diria Bachelard, poderia resgatar em sua inteireza e singularidade.

Contato Extraterrestre permite tecer considerações sobre as relações entre o Poder e a Ciência, ou sobre os temores despertados por um (des)controle desumano e desumanizante dos poderes da Ciência que dizem respeito, em última instância, às formas como apreende-se a realidade.

É certo que todo conhecimento científico é poder. A ciência supõe um certo poder sobre a natureza que se constitui e engendra dentro de determinada constelação histórico-social. Por outro lado, o descontrole da ciência vincula-se à imagem, do senso comum, do cientista manipulador e arrogante, tema caro à literatura gótica inglesa do século XIX e a alguns romances de Júlio Verne.

As promessas emancipacionistas da Ciência que encontram um ponto alto no
Iluminismo, particularmente em Condorcet de Os Progressos do Espírito Humano, cedeu passo no século XIX a um certo ceticismo, paralelo ao dogmatismo comtiano em uma ordem imutável na natureza refletida pelo conhecimento. As leis dos fenômenos em Comte devem traduzir o que ocorre na natureza, sendo estas leis invariáveis. Seus princípios, em suma, seriam:

- as únicas verdades são os enunciados da ciência experimentais (verdades claras, unívocas e imutáveis);

- juízos de valor não são admissíveis;

- a função precípua das ciências experimentais é prever fenômenos e dominá-los.

O positivismo no século $X X$ surge sob novas formas. Particularmente na chamada Escola de Viena, caracteriza-se por associar a tradição empirista ao formalismo da lógica matemática, preconizando como objeto de estudo a análise da relação entre fatos objetivos e a linguagem que busca considerá-los.

Persistem, porém, as desconfianças com relação à ciência, dada a hegemonia positivista ou neopositivista, ao ponto de se criticar a razão tout court, como uma razão excessivamente totalizante, inseparável das "narrativas legitimadoras" (a emancipação do gênero humano, por exemplo). Nessa perspectiva, Lyotard afirma que o sentido da ciência estaria no rompimento com a noção de eficácia e na busca da diferença, do dissenso, do heterogêneo. ${ }^{2}$

Caso se considere as relações entre ciência e sociedade, a inspiração de corte positivista relaciona-se estreitamente com modelos tecnocráticas e decisionistas. No modelo tecnocrático, as decisões cabem aos especialistas; no modelo decisionista, cabem aos políticos, instituições políticas, portanto, determinam objetivos sociais. Os modelos tecnocrático e decisionista podem ser considerados modelos típico-ideais no sentido weberiano, podendo seus traços serem encontrados combinados na realidade 
empírica. ${ }^{3}$ A personagem David Drumlin, dirigente do conselho Nacional de Pesquisa, é exemplar nesse sentido - um misto de cientista e de executivo, seduzido pelo espetáculo midiático, que elabora e implementa políticas, além de aconselhar o PríncipePresidente. Fé no empirismo indutivista, crença na eficácia como legitimadora do fazer ciência, visão instrumental das relações humanas, eis os seus traços essenciais.

$\mathrm{O}$ contraponto perfeito a esta quase caricatura estaria no líder fundamentalista cristão, para quem a Ciência em geral e os seus desdobramentos é a antevisão do Apocalipse: destrói e polui a criação divina. Realizando uma leitura negativa do processo científico e recusando-se a aceitar as conseqüências relativizadoras da modernidade, o fundamentalismo promove a resistência às modernas formas de vida. Através da personagem, a ciência e seu processo fáustico de desenvolvimento é vista como a bête noire, justificando inclusive atos de violência terrorista. De qualquer forma, esta controvérsia, esta tensão, entre o conhecimento religioso e o conhecimento científico já era apontada por Weber. ${ }^{4} \mathrm{O}$ fundamentalismo seria uma reação à pretensão da ciência de representar a única forma possível de uma visão racional de mundo.

Ellie Arroway não poderia ser o contraponto, em um sentido rigorosamente simétrico, a Drumlin, pois compartilha muitos dos seus pontos de vista sobre o fazer científico, guardando uma diferença: um genuíno compromisso com a verdade. Drumlin não hesitaria em sacrificar eventualmente a verdade aos primados dos interesses da política. Ela encontra-se bem mais próxima de uma perspectiva ao estilo de Bachelard - o critério fundamental é a busca da verdade, o próprio conhecimento objetivo, em que pese estar enredado em uma concepção de ciência, que se constitui em verdadeiro obstáculo epistemológico, porque fundada em pressupostos dogmáticos. Seria preciso uma passagem dramática que a libertasse desses pressupostos, baseados na crença de que o caminho proposto pela indução como método levaria ao porto seguro do conhecimento definitivo, juntando cuidadosamente pedaços de informação, em grupo ou isoladamente. Ora aqui há um pressuposto complicado: de que o real seria contínuo e homogêneo. Todavia, o conhecimento tendo por base a indução fracassa, ou pelo menos possui limites como bem aponta Chalmers. ${ }^{5}$ É necessário que nos fragmentos de informação se insinue a imaginação para estabelecer a ligação entre o particular e o universal. Em outras palavras, é necessária uma nova forma de olhar os dados (e por vezes os dados não são necessários a essa nova visão). A teoria pode ser compreendida como uma organização de dados, contemplada por um ato de imaginação, como bem compreendeu a psicologia gestáltica - a percepção é um ato pelo qual organizamos dados soltos e isolados em totalidades significativas, ${ }^{6}$ ou, como diz Polanyi, "a percepção é a compreensão de pistas em termos do todo" (Polanyi in Rubem Alves, p. 154).

Construímos os conceitos com o auxílio da imaginação, sendo a compreensão um processo de construção e reconstrução mental de seus objetos:

“Newton não podia montar e desmontar o universo, Marx não podia montar e desmontar a sociedade. E Freud, igualmente, não tinha poderes para fazer uma dissecação prática da alma. Mas todos fizeram isto, idealmente, através da imaginação." (Rubem Alves, 1981. p. 160)

A imaginação desdobra-se em dois tipos: a exploratória, onde as possibilidades são predeterminadas pelo presente (e que funda a ciência normal, no sentido de $\mathrm{Kuhn}^{7}$ ), e a criadora que traz à luz coisas que não existiam e que busca o que ainda não nasceu e que ainda não foi pensado. ${ }^{8}$

A essa altura, uma pergunta se impõe: em que se enraiza a imaginação? Na necessidade de buscar o sentido, a exigência de ordem que se fundamenta na própria ne- 
cessidade de sobrevivência, pois não existe vida sem ordem e nem comportamento inteligente sem ela:

"A habilidade para prever e predizer os acontecimentos ambientais, de entender o mundo em que se vive e, assim, a capacidade para antecipar eventos e evitar a necessidade de reajustamentos bruscos, é um pré-requisito absoluto para que o indivíduo e mantenha inteiro. O indivíduo deve sentir que ele vive em um ambiente estável e inteligível, no qual ele sabe o que fazer e como fazê-lo..." (Prescott Lecky in Rubem Alves, 1981, p. 36)

Os diálogos entre Ellie Arroway e Palmer Joss, um teólogo secular, crítico da visão pragmática de ciência e assessor da Presidência, sugerem que o conhecimento religioso e o cientifíco possuem uma questão de fundo comum e inarredável: a existência de uma ordem subjacente aos fenômenos, em outras palavras, o conhecimento não nos é dado imediatamente.

A visão de Palmer nasce da intuição poética, de uma exaltação que o faz mergulhar nas coisas e que se enraiza na experiência material elementar.

Em que pese esta aproximação, o desenvolvimento científico, impulsionado pela racionalização das visões de mundo que diferenciam gradativamente esferas axiológicas embutidas na religião (ciência, moral e arte), impõe a criação de métodos que impedem a interposição de pré-conceitos no conhecimento científico. O progresso do conhecimento científico se faz inegavelmente por rupturas com o senso comum, com as opiniões primeiras ou com as prénoções de nossa filosofia espontânea. ${ }^{9}$

O risco reside na reificação dos controles que acabam por obstaculizar o processo contínuo de retificação do saber, pois a ciência se faz contra a experiência, contra a percepção e a atividade técnica usuais.

A experiência de Ellie Arroway que a projeta em outra dimensão de tempo e es- paço e desorganiza toda a sua experiência anterior, estabelece um novo começo, que somente um poeta seria capaz de nomear pela imaginação. $\mathrm{O}$ mundo é belo antes de ser verdadeiro, dizia Bacherlard.

Todo recomeço, porém, é doloroso, colocando em risco a inteireza do ser. Como, então, recomeçar sem destruir-se? De onde retirar a crença na continuidade de sua auto-identidade e na circunstância de seu ambiente circundante? ${ }^{10}$

Esta crença é reposta a partir de lembranças infantis, de experiências de fundo emocional vivenciadas na sua intensa relação com o pai, devido à morte prematura da mãe. A praia de Pensacola, lembrança significativa à Ellie, é recriada e o contato extraterrestre realiza-se mediado pela figura paterna que rememora o passado e delicadamente responde às perguntas de Ellie.

Não há respostas conclusivas; o "pai" de Ellie não sabe quem projetou a máquina e afirma que o feito de Ellie teria sido um primeiro passo na longa jornada dos seres humanos "capazes de sonhos tão lindos e de pesadelos tão horríveis".

Uma indagação crucial, ao menos, foi elucidada: os homens sentem-se sós, mas não estão sós e, paradoxalmente, retorna-se ao ponto de partida: o encontro com outro é o encontro conosco mesmos.

O brilho das estrelas é o brilho das areias de Pensacola e é o brilho do olhar da criança. Somos feitos da poeira das estrelas

\section{Notas}

1 Contato (1997). Cia. das Letras, São Paulo.

2 Lyotard, 1986.

3 Fourez, 1995. Cap. 9 pp. 207-25.

4 Weber, Max. A Ciência como Vocação.

5 Chalmers, 1982. pp. 36-45. 
6 Rubem Alves, 1981. p. 145-153.

7 Kuhn, Thomas. A Estrutura das Revoluções Cientificas.

8 Rubem Alves, 1981, p. 161.

9 Bachelard, 1996.

10 Giddens, 1991, p. 95-102.

\section{Referências}

ALVES, Rubem (1981). Filosofia da Ciência: Introdução ao jogo e suas regras. Editora Brasiliense, São Paulo.

ANDERY, Maria Amélia et al. Para compreender a ciência: uma perspectiva histórica. Rio de Janeiro: Espaço e Tempo: São Paulo: EDUC, 1996 (6. ed. rev. e ampl.).

BACHELARD, Gaston (1996). A Formação do Espirito Científico. Contraponto Editora, Rio de Janeiro.

BERMAN, Marshall (1986). Tudo que é sólido se desmancha no ar: a aventura da modernidade. Cia. das Letras, São Paulo.

CHALMERS (1993). O que é Ciência afinal? Editora Brasi-liense, São Paulo.

FOUREZ, Gérard (1995). A Construção das Ciências. Editora UNESP, São Paulo.

GIDDENS, Anthony (1991). As consequiências da modernidade. Editora UNESP, São Paulo.

LYOTARD, Jean-François (1986). 0 Pós-Moderno. José Olympio Editora, Rio de Janeiro.

ROUANET, Sérgio Paulo (1989). As Razões do Iluminismo. Cia. das Letras, São Paulo.

WEBER, Max. "A ciência como vocação". In Ensaios de Sociologia. GERTH, Hans e WRIGHT MILLS, C. (org.) Rio de Janeiro, Zahar, 1974. 